from that among normal controls and patients with osteoarthritis. Immobility per se does not seem to be a primary factor as the patients with osteoarthritis did not show an increased prevalence compared with the control group.

Certain medical conditions, including pure iron deficiency, uraemia, pregnancy, gastrectomy, and carcinoma, are associated with the syndrome, providing potential clues about its mechanism. ${ }^{3}$ Interestingly, these conditions lead to either pure iron deficiency or anaemia of chronic disease, and anaemic patients experience more severe symptoms. ${ }^{4}$ As patients with rheumatoid arthritis characteristically develop the anaemia of chronic disease the increased prevalence of the syndrome observed in the group with rheumatoid arthritis may relate to this secondary complication. ${ }^{5}$

The combination of the restless leg syndrome and rheumatoid arthritis contributes considerably to discomfort and anxiety, and in our experience few doctors are aware of this condition.

1 Ekbom KA. Restless legs. Acta Med Scand 1945;158(suppl):1-123.

2 Montagna P, de Bianchi L, Zucconi M, Cirknotta F, Lugaresi E. Clonazepam and vibration in restless legs syndrome. Acta Neurol Scand 1984;69:428-30.

3 Lutz EG. Restless legs, anxiety and caffeinism. $\mathcal{J}$ Clin Psychiatry 1978;39:693-8.

4 Ekbom KA. Restless legs syndrome. Neurology 1960;10:868-73.

5 Blake DR, Hall ND, Bacon PA, Dieppe PA, Halliwell B, Gutteridge JMC. The importance of iron in rheumatoid arthritis. Lancet 1981;ii:1142-4.

(Accepted 10 December 1985)

Department of Rheumatology, Selly Oak Hospital, Birmingham B29 6JD

G REYNOLDS, BSC, $\mathrm{MB}$, senior house officer

Rheumatism Research Wing, Medical School, Birmingham B15 2TJ

D R BLAKE, MB, MRCP, senior lecturer and honorary consultant

Neurology Department, Queen Elizabeth Hospital, Birmingham B15 2TT

H S PALL, MB, MRCP, Sheldon clinical research fellow

A WILLIAMS, MD, MRCP, consultant neurologist

Correspondence to: Dr Blake.

\section{Torsade de pointes after astemizole overdose}

Astemizole is a comparatively new long acting antihistamine $\left(\mathbf{H}_{1}\right)$ preparation. Histamine receptors are present in the heart, though their function is not clear.' No case of self poisoning with astemizole has been recorded. I report a case of acute ventricular arrhythmia that occurred after astemizole overdose.

\section{Case report}

A 16 year old girl-presented to the accident and emergency department five hours after swallowing 20 tablets of astemizole (total dose $200 \mathrm{mg}$ ), which had been prescribed for allergic rhinitis ( $10 \mathrm{mg}$ daily). She had vomited several times and claimed not to have taken any other medication or substance. Examination showed nothing abnormal. As she was still vomiting gastric lavage was not performed and she was admitted to the ward for overnight observation.

Seven hours after the overdose she suddenly became unconscious and was found to have no palpable cardiac output. A sharp blow to the sternum restored output and the electrocardiogram monitor confirmed sinus rhythm. She regained consciousness and was transferred to the intensive therapy unit. Pulse was $80 / \mathrm{min}$

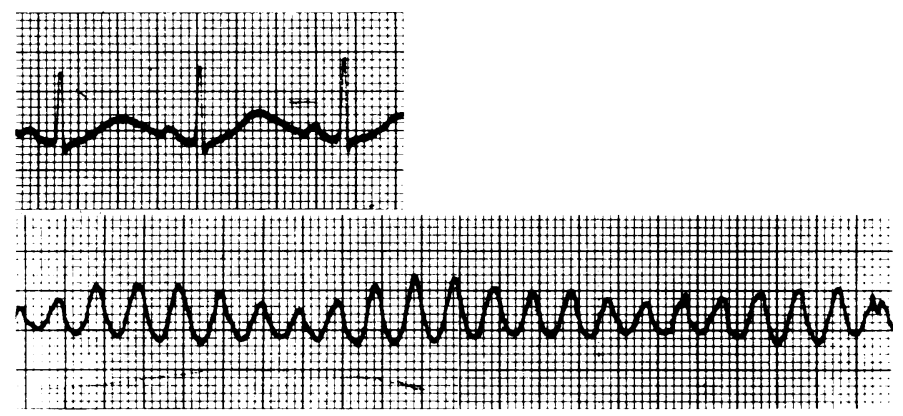

TOP: Standard lead II of a 12 lead electrocardiogram recorded on admission to intensive therapy unit showing $Q-T_{c}$ interval $0.65 \mathrm{~s}$ (paper speed $25 \mathrm{~mm} / \mathrm{s}$ ). воттом: Strip of ventricular tachyarrhythmia characteristic of torsade de pointes (paper speed $25 \mathrm{~mm} / \mathrm{s}$ ). and regular and blood pressure $100 / 60 \mathrm{~mm} \mathrm{Hg}$ supine. There were no signs of cardiac failure or decompensation. One hour later she developed a spontaneous ventricular tachyarrhythmia requiring DC cardioversion with $150 \mathrm{~J}$. Bolus intravenous lignocaine $(100 \mathrm{mg})$ was given and an intravenous infusion of lignocaine begun at $4 \mathrm{mg} / \mathrm{min}$ for 20 minutes, reduced in steps of $1 \mathrm{mg} / \mathrm{min}$ every 40 minutes.

Investigation showed a haemoglobin concentration of $134 \mathrm{~g} / \mathrm{l}$ and a normal white cell count. Serum biochemical values were normal, in particular potassium $4.0 \mathrm{mmol}(\mathrm{mEq}) / 1$, corrected calcium concentration $2.7 \mathrm{mmol} / 1(10.8 \mathrm{mg} / 100 \mathrm{ml})$, and albumin $43 \mathrm{~g} / \mathrm{l}$. Blood and urine sent for analysis to both the poisons unit at New Cross Hospital, London, and the pharmaceutical company marketing astemizole showed results consistent with astemizole overdose. Despite the lignocaine infusion further episodes of ventricular tachyarrhythmia occurred. An amiodarone infusion was therefore substituted with a loading dose of $300 \mathrm{mg}$ followed by an infusion rate of $300 \mathrm{mg}$ over one hour. This also failed to prevent episodes of ventricular tachyarrhythmia.

A 12 lead electrocardiogram recorded on admission to the intensive therapy unit and before the administration of antiarrhythmic agents showed a prolonged Q-T interval (figure). Q-T interval corrected for heart rate $\left(Q-T_{\text {. }}\right.$ ) was $0.65 \mathrm{~s}$ (normal 0.36-0.42 s). Recorded strips of ventricular tachyarrhythmia showed the changing morphology of ventricular complex characteristic of torsade de pointes (figure). An isoprenaline infusion was begun at an initial dose of $1 \mu \mathrm{g} / \mathrm{min}$, which shortened the $Q-T_{c}$ interval to $0.58 \mathrm{~s}$. Seventeen episodes of ventricular tachycardia occurred before the use of isoprenaline, 11 of which did not revert spontaneously or respond to a blow over the sternum and thus required DC cardioversion. One further episode occurred during the isoprenaline infusion. This was controlled by increasing the infusion rate.

Over the next five days the isoprenaline infusion was gradually reduced, the dose being governed by the $\mathrm{Q}-\mathrm{T}_{\mathrm{c}}$ interval. There were no further episodes of torsade de pointes. Serial electrocardiograms showed the $Q-T_{c}$ interval to have reduced to $0.41 \mathrm{~s}$ before the patient left hospital. She was discharged home with advice not to take astemizole in the future. Follow up in the outpatient department confirmed that she was well with a normal Q- $T_{c}$ interval.

\section{Comment}

Torsade de pointes is a recognised complication of treatment with antiarrhythmic agents, whose mode of action includes prolongation of the Q-T interval. Such drugs include membrane stabilisers (for example, lignocaine, flecainide); sotalol, ${ }^{2}$ a $\beta$ blocker with additional group III antiarrhythmic properties; and amiodarone. There are no reports, however, of torsade de pointes occurring after the use of either anti- $\mathrm{H}_{1}$ or anti- $\mathrm{H}_{2}$ antihistamines.

Astemizole is currently used in doses of up to $100 \mathrm{mg} /$ day for mastocytosis. The events after the overdose in this patient (with $200 \mathrm{mg}$ ) question the safety of treatment with high dose astemizole.

I thank Dr P L Golding for permission to report this case.

1 Verma SC, McNeill JH. Cardiac histamine receptors: differences between left and right atria and right ventricle. I Pharmacol Exp Ther 1977;200:352-62.

2 Krapf $R$, Gertsch $M$. Torsade de pointes induced by sotalol despite therapeutic plasma sotalol concentrations. Br Med F 1985;290:1784-5.

(Accepted 30 December 1985

Queen Alexandra Hospital, Cosham, Portsmouth, Hampshire PO6 3LY TIMOTHY M CRAFT, MB, BS, senior house officer in medicine

\section{Exposure to quinalbarbitone sodium in pharmaceutical workers}

Few studies have been reported of exposure to and absorption of drugs among operatives in the pharmaceutical industry. All too often the measures taken to prevent contamination of the product are believed to protect the worker also. In workers manufacturing oral contraceptive pills, however, gynaecomastia and menstrual disorders due to the absorption of ethinyloestradiol have been recorded, ' as has adrenocortical suppression in workers making synthetic glucocorticosteroids. ${ }^{2}$ We report finding a group of workers manufacturing quinalbarbitone sodium who were exposed to the drug and had absorbed measurable amounts, a hazard that would have been overlooked in the absence of biological testing.

\section{Methods and results}

A small pharmaceutical company manufactured quinalbarbitone sodium capsules using semiautomatic encapsulating machines. Filling the machine hoppers with quinalbarbitone sodium powder and inserting empty capsules into moulds were performed by hand. A female process worker developed a rash on 